\title{
Pemberdayaan Masyarakat dalam Mencegah Komplikasi Hipertensi dengan Metode DAGUSIBU Obat-Obat Antihipertensi
}

\author{
Community Empowerment in Preventing Hypertension Complications with the DAGUSIBU \\ Method of Antihypertension Medicines \\ ${ }^{1}$ Lilik Yusetyani, ${ }^{2 *}$ Aghnia Fuadatul Inayah, ${ }^{3)}$ Elva Asmiati \\ ${ }^{1,2,3)}$ Program Studi Farmasi, Fakultas Ilmu Kesehatan \\ Universitas Muhammadiyah Malang \\ Jalan Bendungan Sutami No. 188 Kota Malang \\ *email: aghniainayah@umm.ac.id
}

DOI:

10.30595/jppm.v5i1.9515

Histori Artikel:

Diajukan:

$19 / 01 / 2021$

Diterima:

$10 / 01 / 2022$

Diterbitkan:

$18 / 02 / 2022$

\section{ABSTRAK}

Hipertensi merupakan faktor resiko utama untuk penyakit serebrovaskular seperti stroke, transient ischemic attack, penyakit arteri koroner (infark miokard, angina), gagal ginjal, dementia, dan atrial fibrilasi. Bila penderita hipertensi disertai dengan komplikasi dengan penyakit penyerta tertentu maka akan meningkatkan mortalitas dan morbiditas akibat gangguan kardiovaskularnya tersebut. Kegiatan pengabdian masyarakat ini bertujuan memberikan informasi dan edukasi kepada masyarakat tentang DAGUSIBU dengan harapan dapat mencegah atau menghambat terjadinya komplikasi kardiovaskuler. Pentingnya pemberian informasi dan edukasi tentang penggunaan obat yang benar mempengaruhi tingkat tercapainya tujuan pengobatan. Kegiatan ini diharapkan dapat meningkatkan kepatuhan pasien minum obat. Partisipan pada kegiatan ini adalah seluruh lansia di Posyandu Kelurahan Bandungrejosari Kecamatan Sukun Kota Malang. Metode pendidikan masyarakat mengenai pentingnya kepatuhan minum obat antihipertensi ini diharapkan memberikan manfaat yang cukup efektif. Kartu DAGUSIBU obat ini akan digunakan sebagai media memantau tingkat kepatuhan minum obat antihipertensi. Peserta posyandu yang hadir kegiatan ini terdapat sebanyak $75 \%$ yang memiliki tekanan darah tinggi, hanya sekitar $38 \%$ yang minum obat antihipertensi. Para peserta posyandu meneriman kartu DAGUSIBU dan dimonitoring kepatuhan minum obat setelah satu bulan. Hal ini terlihat dari jumlah pasien posyandu yang patuh minum obat sebesar $60 \%$. Hasil dari metode ini dapat dikatakan cukup efektif untuk memotivasi masyarakat dalam menggunakan obat-obat antihipertensi secara tertib agar tidak jatuh pada komplikasi kardiovaskuler yang membahayakan.

Kata kunci: Obat Antihipertensi; DAGUSIBU; Kepatuhan

\begin{abstract}
Hypertension is a major risk factor for cerebrovascular diseases such as stroke, transient ischemic attack, coronary artery disease (myocardial infarction, angina), kidney failure, dementia, and atrial fibrillation. If hypertension sufferers are accompanied by complications with certain comorbidities, it will increase the mortality and morbidity due to these cardiovascular disorders. This community service activity aims to provide information and education to the public about DAGUSIBU with the hope of preventing or inhibiting cardiovascular complications. Importanceproviding information and education about the correct use of drugs affects the level of achieving treatment goals. This activity is expected to increase patient compliance with medication. Participants in this activity were all elderly people in Posyandu, Bandungrejosari Village, Sukun
\end{abstract}


Lilik Yusetyani, Aghnia Fuadatul Inayah, Elva Asmiati

Pemberdayaan Masyarakat dalam Mencegah Komplikasi Hipertensi dengan Metode DAGUSIBU Obat-Obat Antihipertensi

District, Malang City. This method of community education regarding the importance of adherence to taking antihypertensive drugs is expected to provide quite effective benefits. The DAGUSIBU card of this drug will be used as a medium for monitoring the level of adherence to taking antihypertensive drugs. As many as $75 \%$ of the posyandu participants who attended this activity had high blood pressure, only around 38\% were taking antihypertensive drugs. Posyandu participants receive a DAGUSIBU card and are monitored for medication compliance after one month. This can be seen from the number of posyandu patients who adhere to taking the medicine by $60 \%$.

Keywords: Antihypertensive Drugs; DAGUSIBU; Compliance

\section{PENDAHULUAN}

Hipertensi merupakan penyakit kronik yang ditandai peningkatan tekanan darah persisten dengan nilai sistolik sama dengan atau lebih dari $140 \mathrm{mmHg}$ dan/atau tekanan darah diastolik sama dengan atau lebih dari 90 mmHg (Unger et al., 2020). Pada tahun 2000, hipertensi memiliki prevalensi sebesar 26,4\% dari populasi orang dewasa di seluruh dunia. Prevalensi ini terdiri dari $26,6 \%$ pada populasi pria dan $26,1 \%$ pada populasi wanita. Jumlah penderita hipertensi dewasa diperkirakan akan terus meningkat, dengan peningkatan sebesar 60\% pada tahun 2025 (Tarigan et al., 2018). Prevalensi hipertensi pada usia lebih dari 18 tahun menurut Riskesdas tahun 2013 sebesar 25,8\% (Kemenkes RI, 2019). Berdasarkan Profil Kesehatan Provinsi Jawa Timur tahun 2017, persentase kejadian hipertensi sebesar $20,43 \%$ atau sekitar 1.828 .669 penduduk, dengan proporsi laki-laki sebesar 20,83\% (825.412 penduduk) dan perempuan sebesar 20,11\% (1.003.257 penduduk) (Dinkes Jatim, 2019). Adapun data hipertensi di Kota Malang terdapat 41.591 (9,53\%) kasus dari 689.675 penduduk. Kecamatan Sukun sendiri terdapat 10.165 kasus dari total 5 kecamatan di Kota Malang. Hal ini menunjukkan angka kejadian di Kecamatan Sukun merupakan terbesar di Kota Malang (Dinkes Kota Malang, 2018). Hipertensi itu sendiri merupakan faktor resiko utama untuk penyakit serebrovaskular seperti stroke, transient ischemic attack, penyakit arteri koroner (infark miokard, angina), gagal ginjal, dementia, dan atrial fibrilasi (DiPiro et al., 2015). Bila penderita hipertensi disertai dengan komplikasi dengan penyakit penyerta tertentu maka akan meningkatkan mortalitas dan morbiditas akibat gangguan kardiovaskularnya tersebut.
Terapi farmakologis hipertensi dapat menggunakan obat-obatan antihipertensi. Terapi non farmakologis dapat dilakukan dengan memodifikasi gaya hidup seperti menurunkan berat badan, berhenti merokok, menghindari alkohol, mengurangi stres, memperbanyak olah raga dan istirahat yang cukup. Selain itu, pentingnya pemberian informasi dan edukasi tentang penggunaan obat yang benar mempengaruhi tingkat tercapainya tujuan pengobatan dan mencegah efek samping yang tidak diharapkan. Pemeriksaan tes kesehatan pada lansia juga dilakukan guna memberikan informasi tentang kesehatan tubuh pastisipan supaya dapat meningkatkan kesehatan tubuh dan kualitas hidup. Metode DAGUSIBU yang disampaikan oleh apoteker dan tenaga kesehatan lain dapat memberikan pemahaman pada masyarakat lebih mengetahui tentang cara mendapatkan, menggunakan, menyimpan, dan membuang obat dengan baik dan benar (Assalwa et al., 2019). Berdasarkan latar belakang tersebut, kegiatan pengabdian masyarakat ini bertujuan memberikan informasi dan edukasi kepada masyarakat tentang DAGUSIBU dengan harapan dapat mencegah atau menghambat terjadinya komplikasi kardiovaskuler. Salah satunya dengan meningkatkan pemahaman masyarakat sehinnga kepatuhan minum obat juga meningkat.

\section{METODE}

Kegiatan pengabdian ini menggunakan metode sosialisasi atau pendidikan masyarakat terkait DAGUSIBU obat antihipertensi serta dilakukan pemerikasaan kesehatan. Partisipan pada kegiatan ini adalah seluruh lansia di Posyandu Kelurahan Bandungrejosari Kecamatan Sukun Kota Malang. Materi yang 
disampaikan menggunakan proyektor dan media Microsoft Power Point serta komunikasi dua arah atau pemateri dan peserta dapat berdiskusi. Tahap selanjutnya, para peserta posyandu melakukan cek kesehatan berupa tekanan darah, gula darah dan kolesterol. Tahap terakhir, peserta posyandu konsultasi dengan dokter untuk dilakukan anamnesa, mendapatkan obat dan kartu DAGUSIBU obat yang akan dipantau selama satu bulan. Kartu DAGUSIBU obat ini akan digunakan sebagai media memantau tingkat kepatuhan minum obat antihipertensi, lalu akan dievaluasi dari hasil pencatatan pada kartu tersebut.

\section{HASIL DAN PEMBAHASAN}

Pelaksanaan pengabdian kepada masyarakat dilakukan dalam satu hari dan telah didapat sebanyak 47 subyek lansia dan non-lansia yang dilakukan pemeriksaan kesehatan sesuai prosedur perencanaan. Beberapa problem kesehatan yang perlu dievaluasi dalam pengabdian kepada masyarakat akan ditampilkan pada Tabel 4.1 sampai 4.5 sebagai berikut.

Tabel. 4.1 Jenis kelamin lansia

\begin{tabular}{ccc}
\hline Jenis Kelamin & Jumlah & Persentase \\
\hline Laki-laki & 14 & $42 \%$ \\
Perempuan & 33 & $58 \%$ \\
\hline \multicolumn{1}{c}{ Total } & 47 & $100 \%$ \\
\hline
\end{tabular}

Pada Tabel 4.1 diatas terlihat bahwa jenis kelamin perempuan lebih banyak yaitu 33 subyek (58\%) dibanding laki-laki 14 subyek $(42 \%)$. Hal ini menunjukkan usia paska menopaus pada perempuan lebih rentan untuk kerusakan maupun terjadianya penuaan sel-sel pembuluh darah dan berujung pada hipertensi (Gudmundsdottir et al., 2012).

Tabel. 4.2 Usia lansia

\begin{tabular}{|c|c|c|c|c|c|}
\hline $\begin{array}{c}\text { Usia } \\
\text { (tahun) }\end{array}$ & $\begin{array}{c}\text { Jumlah } \\
\text { L }\end{array}$ & $\begin{array}{c}\text { Jumlah } \\
\text { P }\end{array}$ & $\begin{array}{l}\% \\
\mathrm{~L}\end{array}$ & $\begin{array}{l}\% \\
\mathbf{P}\end{array}$ & $\begin{array}{c}\% \\
\text { Total }\end{array}$ \\
\hline $31-40$ & 1 & 1 & 2 & 2 & 4 \\
\hline $41-50$ & - & 3 & - & 6 & 6 \\
\hline $51-60$ & 3 & 5 & 6 & $\begin{array}{l}1 \\
1\end{array}$ & 17 \\
\hline $61-70$ & 4 & 15 & 9 & $\begin{array}{l}3 \\
2\end{array}$ & 41 \\
\hline$>70$ & 6 & 9 & 1 & 1 & 32 \\
\hline
\end{tabular}

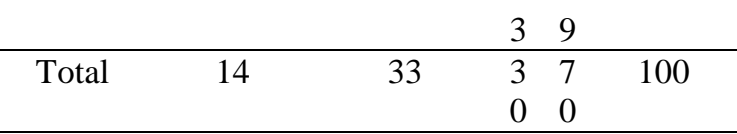

Pengaruh umur terhadap kejadian hipertensi pada saat ini tidak selalu terjadi pada usia lansia, bahkan usia dibawah 30 tahun sering ditemui. Hal ini diakibatkan oleh pengaruh gaya hidup pada usia dewasa muda yang cenderung menyukai makanan siap saji, kemudian merokok sudah dijadikan kebiasaan untuk dikonsumsi (Lu et al., 2015). Pada usia 51-60 tahun hipertensi bisa muncul dari kebiasaan merokok, gaya hidup suka asin dan santan, selain itu juga bisa muncul dari faktor genetik (Pazoki et al., 2018). Pada Tabel 4.2 diatas usia 61-70 tahun dan > 70 tahun menduduki persentase cukup tinggi, pada Tabel 4.2. Faktor usia secara alami bisa memicu terjadinya hipertensi karena kondisi pembuluh dara darah yang mengalami kekakuan, kondisi stres juga berpeluang cukup besar (Cohen et al., 2012). Oleh karenanya, penggunaan obat-obat antihipertensi sudah harus dimulai untuk mengontrol tekanan darah agar selalu normal atau mendekati normal (Unger et al., 2020).

Tabel 4.3 Distribusi derajat hipertensi pada lansia

\begin{tabular}{|c|c|c|c|c|c|}
\hline $\begin{array}{l}\text { Derajat } \\
\text { Hipertensi }\end{array}$ & $\begin{array}{l}\text { Jumlah } \\
\text { L }\end{array}$ & $\begin{array}{l}\text { Jumlah } \\
\text { P }\end{array}$ & $\begin{array}{l}\% \\
\mathrm{~L}\end{array}$ & $\begin{array}{l}\% \\
\mathbf{P}\end{array}$ & $\begin{array}{l}\text { \% } \\
\text { Total }\end{array}$ \\
\hline $\begin{array}{l}\text { Normal } \\
(<120 / 80 \\
\mathrm{mmHg})\end{array}$ & 1 & 11 & 2 & 23 & 25 \\
\hline $\begin{array}{l}\text { Awal/pre } \\
(140 / 90 \\
\mathrm{mmHg})\end{array}$ & 8 & 8 & 17 & 17 & 34 \\
\hline $\begin{array}{l}\text { Derajat I } \\
(160 / 100 \\
\mathrm{mmHg})\end{array}$ & 5 & 8 & 11 & 17 & 28 \\
\hline $\begin{array}{l}\text { Derajat II } \\
(\geq 160 / 100 \\
\mathrm{mmHg})\end{array}$ & - & 6 & - & 13 & 13 \\
\hline Total & 14 & 33 & 30 & 70 & 100 \\
\hline
\end{tabular}

Derajat hipertensi juga menentukan pola terapi tunggal atau kombinasi dalam menurunkan tekanan darah. Penggunaan kombinasi dua atau tiga macam obat anti hipertensi bisa digunakan hingga mencapai target tekanan yang diharapkan (Unger et al., 
Lilik Yusetyani, Aghnia Fuadatul Inayah, Elva Asmiati

Pemberdayaan Masyarakat dalam Mencegah Komplikasi Hipertensi dengan Metode DAGUSIBU Obat-Obat Antihipertensi

2020). Berdasarkan distribusi derajat hipertensi (Tabel 4.3) hampir 75\% subyek telah menunjukkan tekanan darah yang tinggi (preHT (34\%); HT derajat I (28\%); HT derajat II $(13 \%)$. Namun demikian, dari $75 \%$ subyek HT hanya sekitar $38 \%$ yang minum obat antihipertensi (Tabel 4.4). Hal ini cukup mengkhawatirkan untuk terjadinya komplikasi kardiovaskuler bila tidak diobati secaka intensif (Zhou et al., 2018).

Tabel 4.4 Distribusi lansia yang minum obat antihipertensi; obat Herbal; obat non antihipertensi; lansia tak minum obat

\begin{tabular}{|c|c|c|c|c|c|}
\hline $\begin{array}{l}\text { Riwayat } \\
\text { Pengobatan }\end{array}$ & $\begin{array}{l}\text { Jumlah } \\
\text { L }\end{array}$ & $\begin{array}{l}\text { Jumlah } \\
\text { P }\end{array}$ & $\begin{array}{l}\% \\
\mathrm{~L}\end{array}$ & $\begin{array}{l}\% \\
\end{array}$ & $\begin{array}{l}\% \\
\text { Total }\end{array}$ \\
\hline $\begin{array}{l}\text { Minum obat } \\
\text { antihipertensi }\end{array}$ & 4 & 9 & 11 & 27 & 38 \\
\hline $\begin{array}{l}\text { Minum obat } \\
\text { herbal }\end{array}$ & - & 2 & - & 6 & 6 \\
\hline $\begin{array}{l}\text { Minum } \\
\text { vitamin }\end{array}$ & 4 & 7 & 11 & 20 & 31 \\
\hline $\begin{array}{l}\text { Tidak minum } \\
\text { obat }\end{array}$ & 5 & 4 & 14 & 11 & 25 \\
\hline Total & 13 & 22 & 36 & 64 & 100 \\
\hline
\end{tabular}

Dari sebanyak $75 \%$ yang memiliki tekanan darah tinggi, hanya sekitar 38\% yang minum obat antihipertensi (Tabel 4.4). Untuk memperbaiki kualitas hidup pasien lansia, maka pada pengabdian kepada masyarakat kali ini perlu pemberdayaan selalu kontrol tekanan darah dan minum obat bila tekanan darah persisten tinggi. Untuk itu pada pasien yang memiliki tekanan darah tinggi dokter memberikan obat antihipertensi dan selanjutnya untuk dipantau hasilnya.

Tabel 4.5 Profil kepatuhan penggunaan obat antihipertensi untuk lansia

\begin{tabular}{lccccc}
\hline $\begin{array}{l}\text { Kepatuhan } \\
\text { minum } \\
\text { obat }\end{array}$ & L & Pumlah & $\begin{array}{l}\text { Jumlah } \\
\text { P }\end{array}$ & $\begin{array}{l}\text { L } \\
\text { P }\end{array}$ & $\begin{array}{l}\text { P } \\
\text { Total }\end{array}$ \\
\hline $\begin{array}{l}\text { Patuh } \\
\text { Kurang }\end{array}$ & 7 & 14 & 20 & 40 & 60 \\
$\begin{array}{l}\text { patuh } \\
\begin{array}{l}\text { Tidak } \\
\text { patuh }\end{array}\end{array}$ & 4 & 5 & 10 & 14 & 24 \\
\hline \multicolumn{1}{c}{ Total } & 2 & 3 & 6 & 10 & 16 \\
\hline
\end{tabular}

Pemberian terapi antihipertensi oleh dokter merupakan langkah yang harus dilakukan, kemudian diterapkan metode DAGUSIBU untuk obat-obatan yang digunakan. Metode DAGUSIBU didukung dengan penggunaan kartu untuk memantau ketertiban atau kepatuhan dalam menggunakan dan dijelaskan oleh apoteker. Tingkat pengetahuan akan memengaruhi kepatuhan minum obat (Rusida et al., 2017). Kriteria patuh minum obat, bila jumlah obat yang diminum sesuai dengan aturan pakai dan tidak ada lupa minum obat sama sekali. Kurang patuh minum obat bila jumlah obat yang diminum sesuai dengan aturan pakai namun ada lupa minum obat sampai 5 kali. Sementara tidak patuh minum obat bila jumlah obat yang diminum sesuai dengan aturan pakai namun ada lupa minum obat sampai lebih dari 10 kali. Suatu penelitian menunjukkan sekelompok lansia memiliki tingkat kepatuhan yang baik dalam minum obat (Nurhaini et al., 2019).

Metode ini dievaluasi selama 1 (satu) bulan. Hasil dari metode DAGUSIBU terlihat cukup efektif (Tabel 4.5). Hal ini terlihat dari jumlah pasien posyandu yang patuh minum obat sebesar $60 \%$. Metode ini cukup efektif untuk memotivasi masyarakat dalam menggunakan obat-obat antihipertensi secara tertib agar tidak jatuh pada komplikasi kardiovaskuler yang membahayakan (Karnes \& Cooper-DeHoff, 2009).

\section{SIMPULAN}

Penyuluhan dan pemeriksaan kesehatan kepada masyarakat seperti yang dilakukan oleh posyandu sangat penting. Namun, cara penggunaan obat yang benar termasuk kepatuhan masih perlu metode untuk memotivasi masyarakat agar lebih tertib sehingga bisa mencegah terjadinya komplikasi akibat hipertensi. Pemberdayaan masyarakat melalui kegiatan pengabdian masyarakat oleh civitas akademik khususnya dosen farmasi sangat bermanfaat untuk meningkatkan perbaikan kualitas hidup lansia melalui pemeriksaan kesehatan, khususnya pada penyakit hipertensi. Pemberdayaan masyarakat untuk menghindari terjadinya komplikasi penyakit hipertensi melalui metode DAGUSIBU terlihat sangat efektif. 
Lilik Yusetyani, Aghnia Fuadatul Inayah, Elva Asmiati

Pemberdayaan Masyarakat dalam Mencegah Komplikasi Hipertensi dengan Metode DAGUSIBU Obat-Obat Antihipertensi

\section{DAFTAR PUSTAKA}

Assalwa, U., Ningrum, G. P., Tindawati, T. M., Zahro, S., Trisfalia, R. R., Yuliani, A. P., Syarifudin, F., Najah, A. L. N., Devi, A. S., Irmatiara, F., \& Priyandani, Y. (2019). Profil Perilaku Pengelolaan Obat Pada Lansia. Farmasi Komunitas, 8(1), 9-14.

Cohen, L., Curhan, G. C., \& Forman, J. P. (2012). Influence of age on the association between lifestyle factors and risk of hypertension. Journal of the American Society of Hypertension, 6(4), 284-290.

https://doi.org/10.1016/j.jash.2012.06.00 2

Dinkes Jatim. (2019). Profil Kesehatan Jawa Timur 2018. Dinas Kesehatan Provinsi Jawa Timur, 100. https://www.google.com/search?client=fi refox-b-d\&ei=zxpWXtieKq6c4-

EPzvSfyAs\&q=profil +kesehatan+jawa+t imur+2018\&oq=profil+kesehatan+jawa+ timur+2018\&gs_l=psyab.3..0i7i30110.98332.105008..105951... $0.4 . .0 .1459 .7810 .2-$

1j0j2j2j2j3..............gws-wiz.......0i

Dinkes Kota Malang. (2018). Profil Kesehatan Kota Malang Tahun 2018. Dinas Kesehatan Kota Malang, 21.

DiPiro, J. T., Wells, B. G., \& Schwinghammer, T. L. (2015). Pharmacoterapy Handbook. In Laser Focus World (Vol. 44, Issue 8).

Gudmundsdottir, H., Høieggen, A., Stenehjem, A., Waldum, B., \& Os, I. (2012). Hypertension in women: Latest findings and clinical implications. Therapeutic Advances in Chronic Disease, 3(3), 137146.

https://doi.org/10.1177/20406223124389 35

Karnes, J. H., \& Cooper-DeHoff, R. M. (2009). Antihypertensive medications: Benefits of blood pressure lowering and hazards of metabolic effects. Expert Review of Cardiovascular Therapy, 7(6),
689-702.

https://doi.org/10.1586/erc.09.31

Kemenkes RI. (2019). Pusat Data dan Informasi Kementrian Kesehatan RI. 2016. Pusat Data Informasi Kementerian Kesehatan.

https://www.depkes.go.id/article/view/17 092200011/profil-kesehatan-indonesiatahun-2016.html

Lu, Y., Lu, M., Dai, H., Yang, P., SmithGagen, J., Miao, R., Zhong, H., Chen, R., Liu, X., Huang, Z., \& Yuan, H. (2015). Lifestyle and risk of hypertension: Follow-up of a young pre-hypertensive cohort. International Journal of Medical Sciences, 12(7), 605-612. https://doi.org/10.7150/ijms.12446

Nurhaini, R., Hidayati, N., \& Oktavia, W. N. (2019). Gambaran Kepatuhan Minum Obat Pasien Tuberculosis di Balai Kesehatan Masyarakat ( BALKESMAS ) Wilayah Klaten. Sekolah Tinggi Ilmu Kesehatan Muhammadiyah Gombong, 788-795.

http://repository.urecol.org/index.php/pro ceeding/article/view/722

Pazoki, R., Dehghan, A., Evangelou, E., Warren, H., Gao, H., Caulfield, M., Elliott, P., \& Tzoulaki, I. (2018). Genetic predisposition to high blood pressure and lifestyle factors: Associations with midlife blood pressure levels and cardiovascular events. Circulation, 137(7), 653-661. https://doi.org/10.1161/CIRCULATION AHA.117.030898

Rusida, E. R., Adhani, R., \& Panghiyangani, R. (2017). Pengaruh Tingkat Pengetahuan, Motivasi dan Faktor Obat Terhadap Kepatuhan Minum Obat Pasien Hipertensi di Puskesmas Kota Banjarbaru Tahun 2017. Jurnal Pharmascience, 4(2), 130-141. https://doi.org/10.20527/jps.v4i2.5766

Tarigan, A. R., Lubis, Z., \& Syarifah, S. (2018). Pengaruh Pengetahuan, Sikap Dan Dukungan Keluarga Terhadap Diet Hipertensi Di Desa Hulu Kecamatan 
Lilik Yusetyani, Aghnia Fuadatul Inayah, Elva Asmiati

Pemberdayaan Masyarakat dalam Mencegah Komplikasi Hipertensi dengan Metode DAGUSIBU Obat-Obat Antihipertensi

Pancur Batu Tahun 2016. Jurnal

Kesehatan, 11(1), 9-17.

https://doi.org/10.24252/kesehatan.v11i1.

5107

Unger, T., Borghi, C., Charchar, F., Khan, N.

A., Poulter, N. R., Prabhakaran, D., Ramirez, A., Schlaich, M., Stergiou, G.

S., Tomaszewski, M., Wainford, R. D., Williams, B., \& Schutte, A. E. (2020). 2020 International Society of Hypertension Global Hypertension Practice Guidelines. Hypertension, 75(6), 1334-1357.

https://doi.org/10.1161/HYPERTENSIO

NAHA.120.15026

Zhou, D., Xi, B., Zhao, M., Wang, L., \& Veeranki, S. P. (2018). Uncontrolled hypertension increases risk of all-cause and cardiovascular disease mortality in US adults: The NHANES III Linked Mortality Study. Scientific Reports, 8(1), 1-7. https://doi.org/10.1038/s41598-01827377-2 